\title{
Congenital horizontal tarsal kink: a simple surgical correction
}

\author{
N C PRICE AND J R O COLLIN \\ From Moorfields Eye Hospital, City Road, London EC1V2PD
}

SUMMARY A case is reported in which a simple anterior lamellar repositioning procedure was used successfully to repair an upper lid entropion associated with a horizontal tarsal kink. This obviates the need for the more complex and destructive procedures which have previously been described for the treatment of this condition.

Congenital horizontal tarsal kink is a rare form of upper lid entropion. It presents in infancy with trichiasis and secondary blepharospasm, photophobia, and keratitis. It is due to a horizontal kink in the tarsal plate, causing rotation of the marginal 2-3 $\mathrm{mm}$ of tarsus through more than $90^{\circ}$ towards the globe. The skin crease is absent, and the condition may be unilateral or bilateral. Associated systemic abnormalities affecting the cardiovascular and central nervous system have been reported, as in other types of primary upper lid entropion. ${ }^{1}$ The previously reported surgical management of these cases has involved relatively complex lid splitting procedures or excision of part of the tarsus.

We present a case of unilateral congenital horizontal tarsal kink, and describe a simple, effective surgical procedure for its correction.

\section{Case report}

A 6-month-old Caucasian male child was referred for entropion repair. He had been found to have a sticky right eye soon after birth and was treated with several topical antibiotics.

On examination he was found to have a right upper lid entropion with trichiasis and lid retraction. There was no skin crease. No other ocular abnormality was detected, and the left eyelids were normal (Fig. 1).

The child was born at term after an uncomplicated pregnancy and delivery, and there was no ocular family history of note. His neurological development was within normal limits, and no other systemic abnormalities could be found.

At operation he was found to have a horizontal tarsal kink of the right upper lid, which could not

Correspondence to N C Price, FRCS. readily be reduced and was situated $2-3 \mathrm{~mm}$ from the lid margin (Fig. 2). The tarsal kink was corrected by an anterior lamellar repositioning procedure, in which a skin crease incision was made and the anterior lamella of skin and orbicularis undermined to the lash roots. $6 / 0$ Polyglycolic acid sutures were passed through the skin just above the lashes and into the tarsal plate at a higher level, this level being adjusted to provide the desired lid eversion. Levator and Müller's muscles were disinserted from the tarsus to overcome the associated lid retraction and reattached to the anterior lamella by the skin crease sutures to increase the lash eversion ${ }^{2}$ (Fig. 3).

Postoperatively the child recovered well, and eight months after surgery the lid remained at a good level, with the lashes well everted (Fig. 4).

\section{Discussion}

Upper lid entropion is uncommon and almost always due to cicatricial shortening of the tarsoconjunctiva. Surgical repair relies on eversion of the lid margin, with lengthening of the posterior lamella of the lid as required. ${ }^{2}$

Horizontal tarsal kink is a very rare form of upper

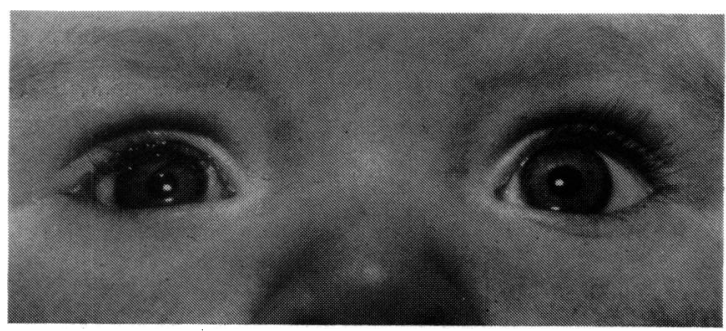

Fig. 1 Preoperative: right upper lid entropion. 


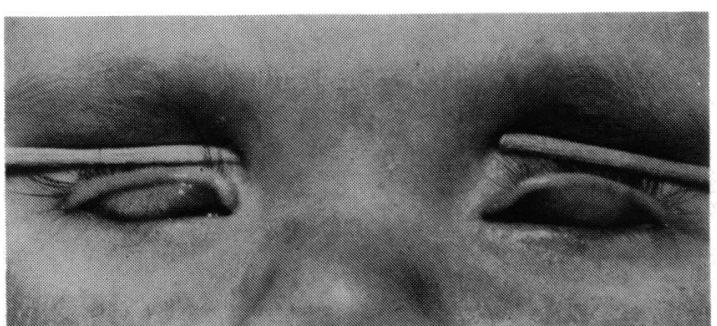

Fig. 2 Everted right upper lid to show horizontal tarsal kink.

lid entropion. Hiles and Wilder ${ }^{1}$ included only two cases in their report of 14 patients with congenital upper lid entropion (one previously reported by Callahan ${ }^{3}$ ), and four other cases have been reported so far. ${ }^{47}$

In five cases presentation was within the first few weeks of life, with inflamed and sticky eyes and blepharospasm. Five patients are said to have had keratitis or frank corneal ulceration at the time of presentation. Three patients had bilateral tarsal kinking, and four, including ours, had abnormalities restricted to the right lid.

The aetiology of the kink is unknown. It has been

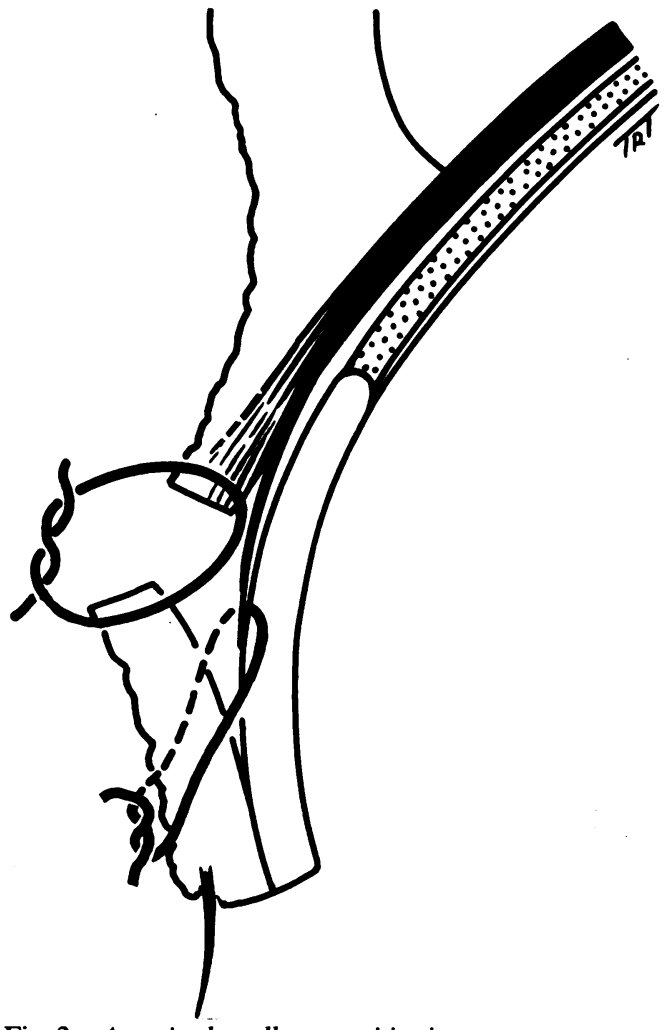

Fig. 3 Anterior lamellar repositioning.

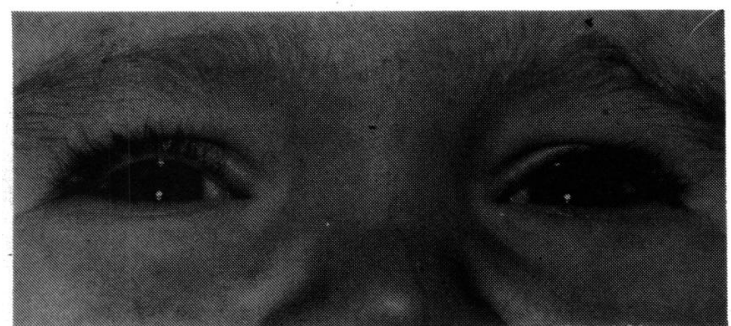

Fig. 4 Eight months after surgery.

suggested that overaction or malpositioning of the marginal fibres of the orbicularis muscle may cause tarsal infolding in utero, and the attachments of the aponeurosis to form the skin crease may be defective. The alternative is a primary lesion in the tarsus itself.

Hiles and Wilder ${ }^{1}$ drew attention to the association of congenital upper lid entropion with other systemic abnormalities, affecting the cardiovascular and skeletal systems and the mental development of six of their 14 patients. More recently $\mathrm{Zak}^{8}$ found multiple cardiovascular, musculoskeletal, and central nervous system abnormalities in a child with congenital primary upper lid entropion. There is no mention of associated abnormalities in the 'tarsal 'kink' papers reviewed, and our child is developmentally normal. However, the incidence of associated developmental abnormalities in children with congenital primary upper lid entropion is such that all children with upper lid entropion should be carefully assessed by a paediatrician, with particular reference to the skeletal, cardiovascular, and nervous systems.

The surgical management of the horizontal tarsal kink has varied in all reported cases. Callahan ${ }^{3}$ and Quickert et al. ${ }^{6}$ advocated resection of the kink and everting sutures. Biglan and Buerger ${ }^{4}$ and Crawford and Main ${ }^{5}$ were concerned that resection of part of the tarsus may cause lid shortening, and treated their patients by horizontal tarsal splitting and everting sutures. McCarthey' carried out a complex lamellar tarsoplasty.

All these procedures were described as successful in correcting the entropion, but all were destructive to the tarsus, either by excision of the part of the tarsal plate or by full-thickness incision through it. Most authors have considered that a simple 'skin and muscle' operation would not provide enough everting strength to hold the tarsus straight, though Hiles and Wilder ${ }^{1}$ have successfully treated one case by such an operation. Kettesy ${ }^{9}$ reported a case of tarsal folding (but not a true horizontal tarsal kink) which was treated by splinting the lid in a normal position with mattress sutures and a bolster of gauze.

In our case, five $6 / 0$ polyglycolic sutures were passed through the skin above the lash roots and into 
the upper part of the tarsus before exiting through the skin again. The eversion produced by such sutures lasts at least two months and allows scarring of the anterior lamella of the lid, which holds the tarsus everted. The eversion is further increased dynamically by attaching the upper lid retractors to the skin edges. The tarsus and meibomian glands are left intact.

In our view horizontal tarsal kink syndrome can be adequately repaired by a simple anterior lamellar reposition without resort to complex and more destructive lid procedures. This supports the view that the primary lesion is in the orbicularis muscle or in the formation of a skin crease and not in the tarsus, since altering the position of the orbicularis muscle and creating a skin crease can cure the condition.

We thank Mr B J Power for kindly referring this patient and agreeing to this publication.

\section{References}

1 Hiles DA, Wilder LW. Congenital entropion of the upper lids. J Pediatr Ophthalmol Strabismus 1969; 6: 157-61.

2 Collin JRO. A manual of systematic eyelid surgery. Edinburgh, London: Churchill Livingstone, 1982.

3 Callahan A. Reconstructive surgery of the eyelids and ocular adnexa. Birmingham, Alabama: Aesculapius, 1966: 37-40.

4 Biglan AW, Buerger GF. Congenital horizontal tarsal kink. Am J Ophthalmol 1980; 89: 522-44.

5 Crawford JS, Main JD. The eye in childhood. New York: Grune and Stratton, 1983: 166-7.

6 Quickert MH, Wilkes TDI, Dryden RM. Non-incisional correction of epiblepharon and congenital entropion. Arch Ophthalmol 1983; 101: 778-81.

7 McCarthey RW. Lamellar tarsoplasty. A new technique for correction of horizontal tarsal kink. Ophthalmic Surg 1984; 15: 859-60.

8 Zak TA. Congenital primary upper eyelid entropion. $J$ Pediatr Ophthalmol Strabismus 1984; 21: 69-73.

9 Kettesy A. Entropion in infancy caused by folding of the tarsus. Arch Ophthalmol 1948; 39: 640-2.

Accepted for publication 16 May 1986. 